\title{
INTRODUCCION AL ESTUDIO DE BERNSTEIN
}

\section{Mario Díaz V. *}

En cierta forma, el trabajo de Bernstein constituye uno de los más importantes esfuerzos sociológicos contemporáneos por establecer una relación entre el poder, las relaciones sociales (y sus principios de comunicación) y las formas de conciencia, y por profundizar en los principios intrínsecos que constituyen y distinguen las formas especializadas de transmisión en el proceso de reproducción cultural de estas relaciones ${ }^{1}$.

Su tesis central, desarrollada durante más de veinticinco años, se refiere tanto a la naturaleza como a los procesos de transmisión cultural y al papel que juega en éstos el lenguaje en los contextos de producción y reproducción, como el trabajo, la familia y la educación. Esta última, es una de las formas que toma el proceso de transmisión y se constituye en un dispositivo de control, reproducción y cambio, configurado por la estructura social.

\section{Esta tesis está compuesta de dos formulaciones fundamentales ${ }^{2}$ :}

1. Cómo los factores de clase regulan la estructura de la comunicación en la familia y por lo tanto la orientación del código sociolingüístico inicial de los niños, y

2. Cómo los factores de clase regulan la institucionalización de los códigos elaborados en educación así como las formas de su transmisión y las formas de su manifestación. (1977: 22).

Esta tesis ha sido, y es, importante no sólo por el interés y la controversia que ha ocasionado sino también por la insistencia y consistencia con la cual se ha intentado resolver una de sus preocupaciones decisivas: "como los códigos (sociolingüísticos o educativos) se generan, reproducen y cambian corno resultado de los rasgos macroinstitucionales de la sociedad, y como se generan, reproducen y cambian en los niveles más específicos de interacción tanto en la familia como en la escuela". Esto explica las continuas transformaciones, variaciones y adiciones en su trabajo sobre el mismo tema, y el carácter unas veces contradictorio de éste ${ }^{3}$.

\footnotetext{
* Profesor Asociado de la Universidad del Valle, Facultad de Educación. Doctor en Sociología de de la Educación de la Universidad de Londres.

${ }^{1}$ La obra de Bernstein se reúne en una serie de tres volúmenes: Class, Codes and Control, Vol. 1, Theoretical Studies Towards a Sociology of Language que es una colección de 11 artículos desarrollados durante un período de 12 años que comenzó en 1958. Aquí, Bernstein intenta mostrar la evolución de su teoría de los códigos sociolingüísticos; Class, Codes and Control, Vol. II. Applied Studies Towards a Sociology of Language, publicado en 1973, es una colección de los resultados de los proyectos de investigación empírica realizados por los miembros de la Unidad de Investigación Sociológica (SRU); entre 1966 y 1971; y Class, Codes and Control Vol. III. Towards a Theory of Educational Transmissions, publicado inicialmente en 1975 y revisado en 1977, es una serie de 8 ensayos que muestran el desarrollo de los conceptos que intentan especificar los principios intrínsecos al código educativo y sus relaciones con el poder y el control. La formulación más específica de su tesis está en "Códigos, Modalidades y el Proceso de Reproducción Cultural: Un Modelo", traducido en Lenguaje y Sociedad, 1984, Universidad del Valle: Centro de Traducciones.

${ }^{2}$ Los desarrollos teóricos iniciales de Bernstein sobre los códigos sociolingüísticos proporcionan las bases para el desarrollo de sus formulaciones sobre los códigos educativos. El punto de unión de estas dos formulaciones o vertientes investigativas que constituyen la tesis general de su obra fue dado en el "Postcript" a la segunda edición del Volumen 1. Sin embargo los conceptos claves referidos a la educación y a la transmisión del conocimiento educativo, fueron planteados previamente en "A Critique of Compensatory Education" (1969), "Social Class, Language and Socialization" (1971) y "Classification and Framing" of Educational Knowladge" (1971).

${ }^{3}$ Como plantea Davies (1976) el carácter metafórico de los conceptos de Bernstein, le han hecho ganar la reputación de ser un autor difícil, cuyas ideas son difíciles de ubicar, han sido mal leídas y mal interpretadas.
} 
Las dos formulaciones de su tesis están complejamente interrelacionadas y en consecuencia la tesis central debe estudiarse como una totalidad que puede distinguirse en diferentes niveles susceptibles de exploración hasta el momento ${ }^{4}$.

El proceso de crecimiento del trabajo de Bernstein, el refinamiento continuo de sus conceptos, la necesidad de operar analíticamente en diferentes niveles lógicos se hace manifiesto en los siguientes rasgos que explican el cambio y crecimiento de su posición teórica:

a)La transformación de los códigos sociolingüísticos en códigos educativos.

b)El paso de un tratamiento descriptivo de la familia y la escuela a un tratamiento analítico de sus funciones en la producción y la reproducción cultural.

c) La inclusión de la escuela y de otras agencias dentro de un campo especializado de reproducción discursiva.

d) Su preocupación creciente por determinar la gramática intrínseca del dispositivo pedagógico considerado como un dispositivo para la producción, reproducción y transformación de la cultura ${ }^{5}$.

\section{Lo Sociolingüístico}

La teoría de Bernstein sobre los códigos sociolingüísticos articula diferentes fases en el proceso de transformación del concepto. En un principio (1958; 1959), el intento por explicar la falta de conocimiento de "las relaciones entre clase social y logros académicos.., entre modos de expresión cognitiva y ciertas clases sociales" conduce a Bernstein a establecer dos formas de lenguaje: un lenguaje público, propio de la clase obrera y un lenguaje formal, propio de la clase media ${ }^{6}$. Cada uno de estos dos lenguajes fue descrito como un conjunto de características aisladas. Así, mientras el lenguaje público se caracterizaba por frases cortas, gramaticalmente simples y a menudo incompletas; son una construcción sintáctica pobre, simple y repetitiva; por el uso simple y repetitivo de conjunciones; por el uso rígido y limitado de adverbios y adjetivos; por el uso infrecuente de pronombres impersonales, el lenguaje formal se caracterizaba por un orden gramatical y sintáctico seguro, que regula lo que se dice; el uso frecuente de proposiciones que indican relaciones lógicas, así como preposiciones que indican contiguidad espacial y temporal; uso frecuente de pronombres impersonales; una discriminación selectiva de adverbios y adjetivos; simbolismo expresivo, etc. ${ }^{7}$. El lenguaje público enfatizaba su dependencia de significados implícitos mientras que el lenguaje formal enfatizaba su dependencia de significados explícitos, independientes del contexto.

\footnotetext{
${ }^{4}$ Bernstein ha planteado en muchas ocasiones que su trabajo debe verse interrelacionado "El trabajo sobre los códigos lingüísticos está vital, e indiscutiblemente interrelacionado con el trabajo de los denominados códigos del conocimiento educativo" (1974:241).

${ }^{5}$ Véase, "Códigos, Modalidades y el Proceso de Reproducción Cultural: Un Modelo", y "Hacia una Teoría del Discurso Pedagógico" en esta publicación, o en este número.

${ }^{6}$ Clase media en el sentido británico. Véase, nota No. 84 en la "Introducción" a Poseer and Ideology in Education, Editado por Jerome Karabel y A.H. Halsey. New York, Oxford University Press 1977.

${ }^{7}$ Dos artículos merecen ser mencionados en esta etapa inicial para el estudio de estas dos formas del lenguaje: "Sorne Sociological Determinantes of Perception" (1968) y "A Public Language: Sorne Sociological Implications of a Linguistic Form” (1959). Según Bernbaum, el trabajo teórico de Bernstein en este entonces reflejaba la actitud sociológica del momento: el énfasis sobre el desperdicio de la potencialidad intelectual de la clase obrera: su inadecuada socialización que reproducía la estratificación social y la búsqueda de soluciones entre los educadores. (Berbaum, 1977:60).
} 
Más tarde, en 1962, Bernstein abandona las nociones de lenguaje público y lenguaje formal y las sustituye por las nociones de códigos elaborados y restringidos ${ }^{8}$. Aquí, los códigos fueron definidos en términos lingüísticos y en términos sicológicos. En el nivel lingüístico, los códigos se referían a "la probabilidad de predicción de los elementos sintácticos para organizar los significados". Los elementos estructurales son más predecibles en el caso del código restringido que en el caso del código elaborado. Para, Bernstein, este paso fue importante en el desarrollo de una teoría sociológica del aprendizaje que indagara el qué y el cómo de] aprendizaje social y las restricciones subsiguientes sobre éste ${ }^{9}$.

La reformulación del lenguaje público y lenguaje formal en los conceptos de códigos elaborados y restringidos pasó de una asociación descriptiva y correlacional entre formas de habla y ciertos atributos demográficos de las familias (1958) tales como niveles de educación, o funciones económicas - aunque poco desarrollada - a una formulación general de los códigos en términos de clase social, poder, la división social del trabajo y el control social.

Los códigos son, entonces, definidos como los principios que regulan los procesos de comunicación, principios que serían funciones de estructuras sociales diferentes. Igualmente, la distinción entre órdenes de significados particularistas y universalistas permitió a Bernstein la combinación de diferentes modelos de comunicación tanto elaborados como restringidos. Así, el código elaborado se definió como particularista en la medida en que su forma sólo estaba al alcance de algunas personas y como universalista en la medida en que sus significados sintetizan medios y fines generales. El código restringido se definió como particularista en la medida en que sus significados sintetizan medios y fines locales y universalista en relación con su modelo de habla, pues todos tienen acceso a este (1974: 78-80; 129). La distinción particularista/universalista es fundamental para desarrollos posteriores del concepto código (véase, "A critique of Conpensatory Education" (1969) en Vol. I).

La definición de códigos del habla, elaborada en 1962 y en "A Sociolinguistic Approach to Socialization" (1965) no sólo establece una relación entre el complejo orden de significados de la estructura social y las formas específicas del habla o códigos, sino que también liga los códigos a las clases sociales y a la división social del trabajo. Si por una parte los códigos son la "traducción lingüística de los significados de la estructura social" por la otra las formas elaboradas y restringidas de estos apuntan hacia la forma como las estructuras de clase -en sociedades industriales avanzadas - actúan sobre la distribución de los significados privilegiados y sobre los procedimientos interpretativos que los generan. Así, "el acceso a los códigos elaborados no depende de factores sicológicos sino del acceso a posiciones sociales especializadas dentro de la estructura social por medio de la cual se hace posible un determinado modelo de habla. Normalmente, aunque no de manera inevitable, estas posiciones coinciden con un estrato que busca o posee el acceso a las áreas importantes de decisión de la estructura social" (1974:79).

Esta formulación también apunta hacia el análisis de las consecuencias educativas y sociales del acceso a códigos diferentes, análisis que se materializará más tarde en la

\footnotetext{
${ }^{8}$ Estos desarrollos se encuentran en "Linguistic Codes, Hesitation Phenomena and Intelligence" y en "Social Class, Linguistic Codes and Grammatica Elements".

${ }^{9}$ En este sentido, Bernstein considera que "una de las tareas de los sociólogos podría ser la de buscar los orígenes sociales de formas lingüísticas particulares y examinar su función regulativa. Esta tarea sería un intento por reducir las interrelaciones entre la estructural social, el uso del lenguaje y la conducta individual. Tal teoría debiera indicar lo que en el ambiente es susceptible de ser aprendido, las condiciones del aprendizaje y las restricciones sobre el aprendizaje subsiguiente". (1974:76).
} 
formulación de su teoría sobre las transmisiones educativas: "El código que el niño trae a la escuela simboliza su identidad social... cuando el niño es sensible al código elaborado su experiencia escolar es una experiencia de desarrollo simbólico y social, para un niño limitado a un código restringido la experiencia escolar es una experiencia de cambio simbólico y social... un cambio en el código envuelve cambios en los medios por los cuales se crean una identidad y una realidad social. Este argumento significa que las instituciones educativas en una sociedad en continuo desarrollo conllevan sus propias tendencias alienantes" (1974: 136). Este planteamiento nos lleva más allá de una formulación de los códigos ligados a atributos particulares de una u otra familia y nos sugiere la importancia que Bernstein asigna a la división social del trabajo del control social de clase mediante el control de la educación.

La distinción de los códigos pasó finalmente a realizarse en términos de la semántica subyacente que regula las realizaciones lingüísticas. La distinción entre código y realizaciones lingüísticas envuelve en este momento la noción de contexto ${ }^{10}$. En 1969, Bernstein discute en "A Critique of the Concept of Compensatory Education" la creciente expansión de este concepto en los años sesenta como una solución a las desigualdades educativas y que desviaban la atención sobre las deficiencias de la escuela hacia las "deficiencias" dentro de la comunidad, la familia y el niño. Contra esta definición Bernstein considera fundamental el estudio de las condiciones y contextos del espacio educativo y de las tensiones que se generan entre éste y otros contextos, como consecuencia de la estructura de significados que la escuela impone. Para Bernstein la escuela orienta a los niños hacia una estructura de significados diferentes que no están muchas veces en correspondencia con el orden de significados que informan la cultura del contexto cultural primario del niño. En este orden de ideas Bernstein distingue dos órdenes de significados: significados independientes del contexto, y significados dependientes del contexto. Los significados dependientes del contexto son implícitos mientras los significados independientes del contexto son explícitos.

En este nuevo sentido, los significados difieren para Bernstein en términos de los contextos que evocan sus realizaciones lingüísticas: Ios significados independientes del contexto son universalistas y los significados dependientes del contexto son particularistas. Igualmente, las realizaciones lingüísticas de los órdenes de significados universalistas son diferentes de las realizaciones lingüísticas de los significados particularistas. Desde esta perspectiva Bernstein considera que "la escuela transmite y desarrolla órdenes de significados universalistas. El trabajo de la escuela es hacer explícitos y elaborar mediante el lenguaje, principios y operaciones, en tanto se aplican a los objetos... y a las personas" (1974:196). La escuela impone y desarrolla el orden de significados universalistas mediante los controles que impone sobre la organización, distribución y evaluación del conocimiento.

La oposición entre significados independientes del contexto, universalistas y explícitos y significados dependientes del contexto, particularistas e implícitos representan en este momento una nueva etapa en el desarrollo del concepto código. El código se define ahora como los principios que subyacen a la orientación de los significados y a su realización lingüística en diferentes contextos ${ }^{11}$. Así, "los códigos elaborados dan acceso a órdenes

\footnotetext{
${ }^{10} \mathrm{Al}$ respecto Bernstein dice: "La búsqueda empírica de las realizaciones contextuales del código junto con la necesidad de construir en sus definiciones básicas la sensibilidad de los contextos socializantes críticos a las realizaciones del habla condujo a una nueva formulación que hizo énfasis en su definición sobre la estructuración social de los significativos relevantes" (1 974:11).

${ }^{11}$ Esta nueva definición establece una diferencia entre códigos y realizaciones, entre código y variantes del habla. "Las variantes del habla, en la teoría, representan la estructura superficial mientras que el código representa la estructura profunda" (1974:15). Mientras que las variantes del habla son patrones de selecciones que son específicas para un contexto el código se refiere a la estructura profunda que controla dichas realizaciones". El código, pues, presupone reglas subyacentes que controlan la generación de Digitalizado por RED ACADEMICA
} 
de significados universalistas que están menos ligados al contexto mientras que los códigos restringidos dan acceso a órdenes de significados particularistas que están más ligados a un contexto particular" (1974:197). Los códigos a diferencia de las variantes del habla se refieren a las reglas subyacentes de interpretación que regulan la orientación hacia un orden de significados que sustantivan una cultura. La definición más específica de código en términos de la semántica subyacente fue presentada por Bernstein en "Codes, Modalitis and the Process of Cultural Reproduction: A Model" (1981) (reproducido en este número) ${ }^{12}$. El código se define como "un principio regulativo tácitamente adquirido que selecciona e integra: a) significados relievantes; b) la forma de su realización y c) contextos evocadores". Desde este punto de vista, el código controla la especialización y distribución de los diferentes órdenes de significados y la especialización y distribución de los contextos en los cuales estos se realizan. Así, si querernos entender la producción, reproducción y transformación de órdenes de significados legítimos, necesitamos establecer las bases sociales (distribución del poder y principios de control) que regulan la distribución y demarcación de contextos especializados. Es, desde este punto de vista, que Bernstein plantea que el código es un regulador de las relaciones entre contextos y a través de esto de las relaciones dentro de los contextos (1981:5). En estos, el código regula las reglas especializadas de la comunicación y demarca las comunicaciones legítimas de las comunicaciones ilegítimas.

Con el propósito de crear códigos específicos, Bernstein re-escribe la definición general en la siguiente forma:

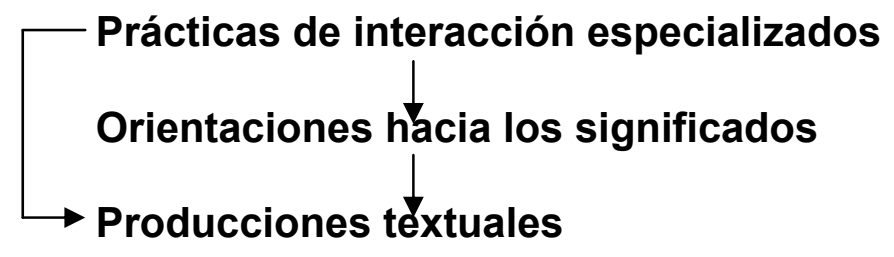

(contextos)

(significados)

(realizaciones

La orientación hacia los significados se entiende en términos de relaciones referenciales privilegiadas/privilegiantes. Así, los significados son privilegiados en el sentido en que el acceso a estos está mediado por el poder en una escala dominante/dominado, $y$ en el sentido en que sus contextos estén jerárquicamente demarcados Podemos distinguir dos orientaciones hacia los significados:

1. Orientación elaborada, donde existe una relación indirecta entre los significados y una base material específica, $y$,

2. Orientación restringida, donde existe una relación directa entre los significados y una base material específica.

La definición de orientaciones hacia los significados -elaboradas y restringidas - es el resultado de las transformaciones del concepto significado implícito y significado explícito $^{13}$, en significados universalistas y particularistas ${ }^{14}$, y mas tarde en significados

\footnotetext{
significados en contextos diferentes. En este sentido lo que observamos son los textos, las variantes del habla o formas de habla) para expresar los significados, lo que inferimos son las reglas subyacentes del código que regulan la generación de dichas variantes del habla. Véase "Postcript" al Vol. I.

${ }^{12}$ Esta definición fue anticipada en 1977 en el artículo "On the Relations between Education and Production” y en el Prólogo a Code in Context de Diana Adlam, asistente de la SRU. Previamente Bernstein había distinguido en 1973 el concepto de reglas subyacentes del código. En 1977 dirige su atención hacia las regias de actuación. Ambas reglas subyacen a la conducta manifiesta de los eventos de la comunicación. En esta nueva definición de código, Bernstein transforma las reglas subyacentes y de actuación en reglas de reconocimiento y de realización. (Véase ruta anterior).

${ }^{13}$ Formulados en 1958 en "Some Sociological determinante of perception" en Class, Codes and Control, Vol. 1.

${ }^{14}$ Formulados en 1962 en "Linguistic codes, hesitation phenomena and intelligence" en Class, Codes and Control, Vol. 1.

Digitalizado por RED ACADEMICA
} 
independientes/significados dependientes del contexto ${ }^{15}$. Es importante anotar que esta definición presenta de manera más explícita las relaciones entre la orientación hacia los significados, su ubicación, distribución y sus orígenes y la distribución del poder creada por la división social del trabajo. Para Bernstein, la ubicación y distribución de los orientaciones hacia los significados estaba determinada por los principios de la división social del trabajo del modo de producción. Así, "entre más simple sea la división del trabajo más específica y local será la relación entre un agente y su base material y por lo tanto más directa será la relación entre los significados y una base material específica y más restringida la orientación hacia la codificación... y entre más compleja sea la división social del trabajo menos específica será la relación entre un agente y su base material, más indirecta la relación entre los significados y una base material específica y más elaborada será la orientación hacia la codificación" (1981:9). En esta forma las orientaciones de la codificación son inherentes a las posiciones (ubicación) de los agentes en la división social del trabajo de producción. Las orientaciones hacia la codificación son específicas y especializadas para una ubicación (posición) particular. Así, las ubicaciones diferentes en el modo de producción generan prácticas de interacción diferentes que realizan relaciones diferentes con una base material y, de esta manera, diferentes orientaciones de la codificación. Si las orientaciones de la codificación son especializadas y relacionadas con la ubicación en la división social del trabajo, la condición para que esto ocurra son las relaciones de clase. Las relaciones de clase especializan las orientaciones de la codificación en la división social del trabajo del modo de producción. En esta forma la distribución del poder que surge de las relaciones de clase determina la relación entre las orientaciones de la codificación y la ubicación en la división social del trabajo.

Para Bernstein, las orientaciones hacia los significados (orientaciones de la codificación) se ubican, distribuyen, legitiman y reproducen tanto en, como por medio de, el modo de producción aun cuando no tienen sus orígenes en este. Los orígenes de las orientaciones elaboradas y restringidas según el autor, se encuentran en las agencias de control simbólico. Si la ubicación y distribución de las orientaciones elaboradas son reguladas por el modo de producción sus orígenes descansan en los sistemas religiosos y en las cosmologías que estos crearon. (Véase 1981:9).

¿Cómo se regulan las realizaciones de las orientaciones hacia los significados? Los principios que regulan las realizaciones de las orientaciones hacia los significados son intrínsecos a las prácticas de interacción (contextos), las cuales se componen de dos rasgos inter-relacionados: la división social del trabajo y sus relaciones sociales intrínsecas.

Bernstein utiliza el concepto de clasificación para referirse al principio que regula la división social del trabajo y el concepto de enmarcación para referirse al principio que regula sus relaciones sociales. Estos conceptos se definen más adelante. (Véase, también "Clasificación y enmarcación del Conocimiento Educativo", en este número).

En resumen, podemos observar en la formulación sociolingüística, dos aspectos fundamentales. Por una parte, la precisión creciente en el desarrollo de una conceptualización sobre los códigos y por articular el proceso de su generación, reproducción y cambio como consecuencia de los cambios en la estructura social

\footnotetext{
${ }^{15}$ Formulados en 1969 y en 1971. en "A Critique of the Concept of Compensatory Education" y en "Social, Class, Language and Socialization" en Volumen 1. En esencia, los significados independientes del contexto son significados que tienen una relación indirecta con una base material específica. Los significados dependientes del contexto tienen al contrario una relación directa con una base material específica. Según Bernstein, el problema con el concepto "independiente del contexto" consistía en que nada en la lengua es independiente del contexto. En este sentido la noción "independiente del contexto" no es absoluta sino relativa. 
(cambios en el nivel macro) y, por la otra, la continua articulación entre los códigos sociolingüísticos y los denominados códigos educativos. Las referencias continuas a la educación - y a la familia - corno agencias de transmisión, la relación que establece entre la escuela y la transmisión y desarrollo de órdenes de significado universalistas (códigos elaborados) y la articulación entre estos y las relaciones de poder creadas fuera de la escuela permiten a Bernstein internarse en el desarrollo de una teoría de las transmisiones educativas de los códigos elaborados.

\section{De lo Sociolingüístico a lo educativo}

Los desarrollos teóricos de Bernstein sobre los códigos educativos se inscriben dentro de un proceso de búsqueda de conceptos que dieran cuenta de las relaciones de poder (fundamentadas en las relaciones de clase) inscritas en el acceso a, control y cambio, de los sistemas simbólicos*, y en consecuencia, de los límites de la experiencia.

El desarrollo de estos conceptos permitió establecer la gramática profunda que regula la distribución social de los significados especializados en el contexto escolar y los procesos selectivos de su organización, transmisión y evaluación. Igualmente, y desde otra perspectiva, esta búsqueda de la gramática generativa de las transmisiones educativas -y de la reproducción cultural- contribuyó al fortalecimiento de las posiciones críticas de lo que se denominó "la nueva Sociología de la Educación"16.

El análisis sobre los principios de transmisión y sobre su incorporación en las estructuras de las relaciones sociales sufrió en Bernstein, desde 1964, continuas transformaciones. En su interés por construir estos principios, Bernstein presenta tipos ideales y conflictivos que permitieren mostrar el contraste entre patrones de características estructurales en la cultura escolar y su relación con el orden social, la división social del trabajo y la estratificación social. Así, Bernstein distingue inicialmente, en la cultura escolar dos órdenes: un orden instrumental (que transmite habilidades académicas) y un orden expresivo (que transmite actitudes y valores) ${ }^{17}$. Estos desórdenes son descritos en términos de un conjunto de oposiciones que son vistas por el autor más como oposiciones dialécticas que como dicotomías.

Las tensiones y conflictos entre estos dos órdenes se analiza más tarde en términos de las oposiciones consensual/diferenciado, estratificado/diferenciado. En "Ritual in Education" (1966) Bernstein distingue entre dos estructuras organizativas diferentes para la transmisión del orden instrumental y del orden regulativo. Las relaciones sociales de transmisión de estos dos órdenes pueden generar y reproducir estructuras estratificadas que celebran el status y la jerarquía, o estructuras diferenciadas, menos jerarquizadas. El cambio en las estructuras de la escuela y de las formas de transmisión de estos dos órdenes estaría ligado a cambios en la división social del trabajo y al cambio en las funciones de la escuela con respecto a las demandas económicas y de control social ${ }^{18}$.

\footnotetext{
* "Sistemas simbólicos" entendidos corno "capital cultural".

${ }^{16}$ Con el desarrollo de su teoría sobre las transmisiones educativas Bernstein contribuyó a los desarrollos críticos de la "Nueva Sociología de la Educación” y a sus representantes, Young, Keddie, Sharp y Green, y a otros como Bordeieu. Una introducción interesante a este tema puede encontrarse en Jerome Karabel y A.H. Halsey Power and Ideology in Education, New York, Oxford University Press. 1977.

${ }^{17}$ Véase. "Sources of Consensus and Disaffection in Education", 1964 en Bernstein (1977).

${ }^{18}$ Bernstein comenta al respecto: "El cambio en la escuela de una estructura estratificada a una estructura diferenciada puede entenderse corno el cambio de un orden social que descansa sobre la dominación a un orden que descansa sobre la cooperación. Este cambio probablemente se relaciona con, y es similar al cambio en el carácter de las relaciones laborales en una sociedad industrial avanzada" (1974:63).
} 
La distinción entre estratificado y diferenciado es remplazada posteriormente por la oposición entre abierto y cerrado. Así, en "Open Schools —Open Society" (1967), Bernstein influido por la interpretación Durkheimiana sobre la solidaridad orgánica y la solidaridad mecánica examina las formas de control y la división social del trabajo en la escuela y los límites que demarcaciones (abiertas y cerradas) que en estas se generan como consecuencia en el cambio en los principios de integración social — de la solidaridad orgánica a la solidaridad mecánica-. La oposición abierto cerrado representa, en este caso, los límites rígidos (fuerza de las categorías) o flexibles (mezcla de las categorías) dentro de, y, entre los dos órdenes: "la idea era producir una escala de grados de apertura y cierre que permitiera analizar la escuela. Uno podría examinar los cambios concomitantes en el orden expresivo con grados diferentes de cambio en el orden instrumental, y viceversa.., de nuevo insistiría que este cuadrante (instrumental! expresivo, abierto/cerrado) no es un simple asunto de dicotomías sino de posiciones que están en conflicto" (1977:7).

El análisis de estas oposiciones, junto con el desarrollo de los conceptos de la división social del trabajo y de la diferenciación social, ocupacional y educativa permitieron generar finalmente los conceptos de clasificación, enmarcación y código educativo. Estos conceptos sustituyen e incluyen las oposiciones anteriores, integran los rasgos estructurales (paradigmáticos) e interaccionales (sintagmáticos) de la transmisión y tienen su fundamento en la distribución del poder y los principios de control ${ }^{19}$. Igualmente los conceptos permitieron pasar de un análisis centrado en tipologías y modelos en oposición o conflicto de los eventos educativos a un análisis de los principios subyacentes de la transmisión cultural en diferentes niveles.

Bernstein caracterizó la importancia de los conceptos de clasificación y enmarcación, en la siguiente forma:

A través de la definición de los códigos educativos en términos de relaciones de poder y control entre la clasificación y la enmarcación, estos dos componentes se construyen en el análisis de todos los niveles. De esta manera se hace posible derivar en un marco de trabajo una tipología de los códigos educativos, mostrar las interrelaciones entre las propiedades organizativas y las propiedades del conocimiento, pasar del nivel de análisis macro al nivel micro, relacionar los patrones internos de instituciones educativas con los antecedentes sociales externos de tales patrones, y considerar los problemas de estabilidad y cambio (1977:112).

Los conceptos de clasificación, enmarcación y su aplicación al control sobre la distribución de los órdenes de significado y sobre las reglas especializadas de su transmisión en la escuela (pedagogías) fue en cierta forma el comienzo de una teoría sobre la gramática profunda que constituye y distingue las formas especializadas de transmisión cultural, la división social del trabajo de sus agencias y agentes, y sus relaciones sociales intrínsecas. Estos desarrollos se insinúan en "Clases y Pedagogías: Visibles e Invisibles" (en este volumen). A continuación definimos con más detalle los conceptos de clasificación y enmarcación.

\footnotetext{
${ }^{19}$ Los desarrollos de estos conceptos se encuentran en los artículos "On the Curriculum" (1969) y "On the Classificacion and Framing of Educational Knowledge” (1971), (incluido en este volumen).
} 


\section{Clasificación}

En un nivel abstracto clasificación $(C)$ se refiere a la relación entre categorías. Las categorías son creadas por la división social del trabajo. La relación entre las categorías está dada por el grado de aislamiento que se da entre ellas. El grado de aislamiento es el regulador fundamental de las relaciones entre las categorías y de la "especialidad de sus voces". Así, cuando hay un fuerte aislamiento entre las categorías (agencias, agentes, discursos, sitios) esto es, cuando existe una clasificación fuerte $(+C)$ cada categoría esta perfectamente aislada, distinguida, o diferenciada, esto es, "cada categoría posee su identidad específica y sus propios límites". Cuando el aislamiento es débil (clasificación débil, o $\mathrm{x}-\mathrm{C}$ ), las categorías son menos especializadas, su especialidad se reduce considerablemente y es posible encontrar una mezcla entre éstas. En esta forma, el principio de clasificación presupone aislamientos estructurales (fuertes o débiles) entre categorías (agentes, agencias, discursos). Para Bernstein, son las relaciones de poder las que crean, legitiman, mantienen y reproducen el aislamiento entre las categorías; en esta forma, todo cambio en el aislamiento entre las categorías implica un cambio en sus relaciones de poder y por lo tanto un cambio en el principio de clasificación (de $+\mathrm{C} a-\mathrm{C}$ ), esto es, un cambio en el principio de la división social del trabajo. Así, si examinamos el campo educativo, observamos que éste está compuesto por un conjunto complejo de categorías (maestros, alumnos, discursos/significados, escuelas, niveles, etc.) que se encuentran sujetas al principio de clasificación y distribución. Dicho principio realiza la división social del trabajo del campo educativo y genera las relaciones de poder entre sus diferentes categorías. Tenemos entonces que si queremos comprender la producción, reproducción y transformación de una determinada clasificación necesitamos analizar las bases sociales que fundamentan una determinada distribución del poder, esto es, la división social del Trabajo. Con referencia al conocimiento educativo, el principio de clasificación se refiere al "grado de mantenimiento de los límites" entre los diferentes órdenes de conocimiento que transmite la escuela. El principio de clasificación establece los controles sobre la distribución de los conocimientos y en esta forma la distribución de formas de conciencia. En otros términos, el principio de clasificación establece las relaciones entre poder y conocimiento y entre conocimiento y formas de conciencia. En síntesis, para Bernstein, el principio de clasificación regula la relación entre la distribución del poder y la distribución del conocimiento y la distribución de las formas de conciencia (Véase, "Clasificación y Enmarcación..." y "Códigos, Modalidades...").

\section{Enmarcación}

La enmarcación se refiere al principio que regula las relaciones sociales, esto es, al principio que subyace a las prácticas de comunicación. La en-marcación nos remite a la interacción, a las relaciones de poder de la interacción, a los límites de la interacción. Enmarcación presupone comunicación. La enmarcación constituye, legitima y mantiene la estructura de las relaciones comunicativas en las cuales siempre está presente el control. La enmarcación vehicula los principios de control que reproducen los límites establecidos por una clasificación.

Bernstein dice que en la misma forma que las relaciones entre categorías están reguladas por una clasificación fuerte o débil, de la misma manera los principios de comunicación pueden estar regulados por una enmarcación fuerte o una enmarcación débil. Tenemos pues que los principios de comunicación (relaciones sintagmáticas) pueden variar en grados diferentes, lo que no varía es el control el cual está siempre presente. La forma que el control toma se describe en términos de enmarcación. En esta forma, cambios en la enmarcación producen cambios en los principios de comunicación, 
cambios en las modalidades de control y cambios en el contexto comunicativo. En la misma forma que la distribución del poder regula el principio de clasificación mediante la división social del trabajo, los principios de control regulan la enmarcación mediante sus relaciones sociales (Bernstein: 1981:22).

\section{Enmarcación y prácticas pedagógicas}

Para Bernstein, la enmarcación $(E)$ se refiere al principio que regula las prácticas pedagógicas de las relaciones sociales creadas en el proceso de reproducción del conocimiento educativo. Las prácticas, constituyen, regulan y relacionan las posibilidades de dos principios comunicativos: el principio interaccional y el principio locativo. En la escuela, entonces, la enmarcación se refiere al control sobre las prácticas comunicativas (selección, secuencia, ritmo de la transmisión) producidas en la relación pedagógica (Véase Clasificación y Enmarcación en este volumen).

Cuando la enmarcación es fuerte $(+E)$ el maestro explícitamente regula los rasgos distintivos de los principios interaccional y locativo que constituyen el contexto comunicativo, (transmisiones específicas $\mathrm{y}$, ordenamients espaciales y posiciones específicas). Cuando el enmarcamiento es débil (-E) el aprendiz tiene un mayor control sobre la regulación de los principios comunicativo y locativo. La enmarcación también se refiere a las relaciones sociales entre contextos comunicativos diferentes como por ejemplo la relación entre la familia, o la comunidad, y la escuela. La en-marcación regula lo que cuenta como comunicación legítima en relación pedagógica y en esta forma lo que cuenta como prácticas pedagógicas legítimas.

Tenemos, entonces, que para Bernstein la distribución del poder regula los principios de clasificación y, por lo tanto, la división social del trabajo de las agencias, agentes y discursos; y que los principios de control regulan la enmarcación y por lo tanto las relaciones sociales de las prácticas de transmisión cultural. La articulación de la clasificación y la enmarcación dan cuenta del código y constituyen su gramática. Las relaciones de poder constituyen, legitiman y mantienen las clasificaciones del código (rasgos paradigmáticos) y las relaciones de control constituyen, mantienen y legitiman la enmarcación de las relaciones comunicativas (rasgos sintagmáticos). En esta forma, los códigos "son transformaciones en gramáticas/ principios semióticos de las relaciones y realizaciones de categorías, donde sus relaciones representan lo paradigmático y sus realizaciones representan lo sintagmático" (1981:30).

\section{Códigos y modalidades: su escritura}

Los códigos específicos pueden ser especificados mediante la siguiente formula: (Bernstein 1981).

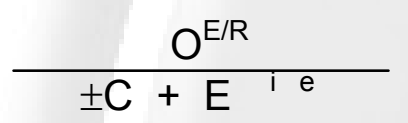

donde:

O Se refiere a las orientaciones elaboradas/restringidas. Como hemos anotado anteriormente, las orientaciones elaboradas y restringidas se crean y legitiman mediante la división social del trabajo del modo de producción que produce y reproduce la clasificación fuerte entre el trabajo manual y el trabajo mental. Dicha distribución se transfiere a la familia y a la escuela. En esta última, la distinción entre 
orientaciones elaboradas y restringidas reside en el carácter de las relaciones que se dan entre las formas de conocimiento y la división social del trabajo creada para su transmisión/reproducción. Compárese por ejemplo la educación académica frente a su opuesta la educación de capacitación técnica para formar mano de obra.

C Se refiere al principio de clasificación que, como hemos dicho, sustantiva las relaciones de poder.

E Se refiere al principio de enmarcación, el cual sustantiva las formas de control que funcionan en cualquier contexto de interacción.

+ Se refiere a los valores de la clasificación y de la enmarcación. \pm significa fuerte y significa débil.

i/e $i$ se refiere a los valores internos de la enmarcación, dentro de un contexto comunicativo, bien sea la familia, la escuela, el trabajo.

e se refiere a los valores externos de la enmarcación, esto es, a la regulación de las relaciones comunicativas entre contextos comunicativos como por ejemplo las relaciones entre familia o la comunidad y la escuela, o las relaciones entre la escuela y el trabajo, o entre la familia y el trabajo.

Las variaciones del código (sus modalidades) dependen de las variaciones de la clasificación y de la enmarcación. A su vez, las variaciones en los valores de $\mathrm{C}$ o $\mathrm{E}$ celebran las variaciones en la distribución del poder y los principios de control. En esta forma podemos decir que el código es la gramática profunda que regula tanto las estructuras y relaciones de poder como la forma de su transmisión/adquisición en diferentes contextos comunicativos de agencias de producción o reproducción tales como la familia, la educación, o el trabajo. Esto es, el código y sus modalidades $(+\mathrm{C}+\mathrm{F})(-\mathrm{C}-\mathrm{F})$ $(+\mathrm{C}-\mathrm{F})(-\mathrm{C}+\mathrm{F})$ establecen una relación fundamental entre una distribución dada del poder y su realización en prácticas de interacción/comunicación. De esta manera, las posibilidades de realización de un contexto están dadas por los principios que regulan la clasificación y la enmarcación de sus prácticas comunicativas. En un esquema muy simple podemos especificar estas relaciones. 


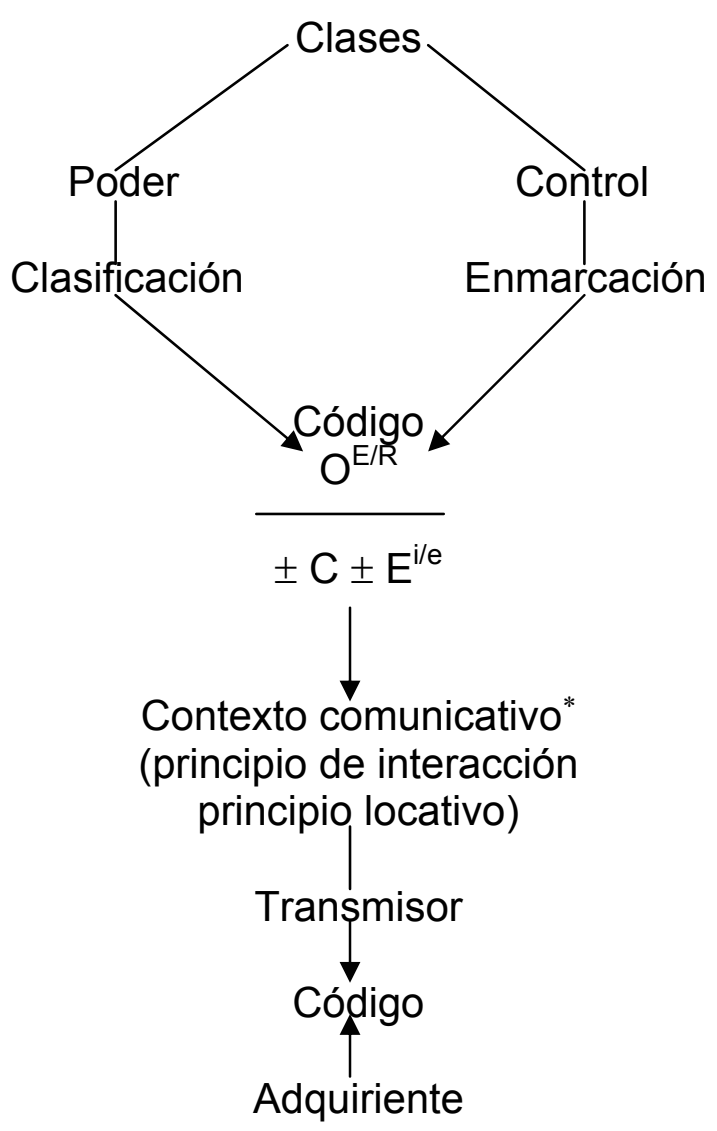

Los cambios en la distribución del poder y/o en los principios de control actúan selectivamente sobre los valores intrínsecos del código el cual a su vez regula las posibilidades (estructura e inter-acciones) de los contextos comunicativos de las agencias de producción o de control simbólico. Es en este sentido que Bernstein plantea que "Las modalidades del código son esencialmente variaciones de los medios y enfoques del control simbólico sobre las bases de una distribución dada del poder" (1981: 28). Los códigos (sociolingüísticos o educativos) son principios reguladores que se adquieren tácitamente en el proceso de socialización. En este sentido el código es un regulador simbólico de la conciencia que condensa en su gramática la distribución del poder y los principios de control. Es mediante los códigos que una lógica de transmisión/adquisición se regula, que una experiencia particular se produce y que una identidad social específica se legitima.

\section{Códigos y reproducción cultural}

Tanto la tesis sociolingüística como la tesis sobre las transmisiones educativas forman en Bernstein parte de sus análisis sobre las estructuras que subyacen a la reproducción de las relaciones de clase. Hemos visto que, por una parte, las relaciones de clase configuran la estructura de la comunicación "y sus bases sociales" en la familia y, por la otra, regulan la institucionalización de los códigos elaborados en la escuela. Los

\footnotetext{
* Para Bernstein todo contexto comunicativo o socializante se compone de un transmisor y de un adquiriente. Estos dos forman una matriz socializante cuyos principios subyacentes se realizan en los valores de la clasifícación y de la enmarcación. Una matriz socializante (maestro/alumno, padre/hijo, etc.) puede ser una matriz reproductora, una matriz interruptora, o bien, una matriz de cambio.
} 
conceptos de clasificación, enmarcación y código nos permiten comprender los procesos de reproducción que crean mediante la comunicación, demarcaciones, diferencias y posiciones entre y dentro de los sujetos. Mediante los códigos el sujeto incorpora la estructura social.

Los códigos condensan en su gramática la distribución del poder y los principios de control intrínsecos a las relaciones de clase: "Poder y control se hacen sustantivos en la clasificación y enmarcación que a su vez generan distintas formas de relación social y de comunicación mediante las cuales se configuran, aunque no de manera final, las estructuras mentales" (Bernstein, 1977: 11). Es en este sentido que puede decirse que los códigos son dispositivos de reproducción cultural. Podríamos agregar que el proceso de reproducción cultural se cumple mediante la selección e institucionalización de los principios subyacentes del código: La clasificación y la enmarcación. Estos principios permanecen activos en el proceso de socialización. Así pues, la estructura de la socialización, como Bernstein plantea, no es un conjunto de roles sino relaciones de clasificación y en-marcación mediante las cuales se incorpora lo social y se transforman sus relaciones sociales internas al sujeto.

En esencia, podemos decir que los códigos son dispositivos complejos y especializados de reproducción cultural constituidos por una gramática ubicadora especializada cuyos principios y reglas son el resultado de las relaciones de clase o de principios dominantes equivalentes. "Los códigos se refieren a gramáticas semióticas reguladas por distribuciones del poder y principios de control especializados ... son gramáticas semióticas específicas que regulan la adquisición, reproducción y legitimación de reglas fundamentales de exclusión, inclusión y apropiación, por medio de las cuales los sujetos son selectivamente creados, puestos y opuestos entre sí" (Bernstein 1981: 30-31).

\section{REFERENCIAS}

BERNSTEIN, B. (1977). Class, Codes and Control, Vol. 3. Towards a Theory of educo tional transmissions. London: R.K.P.

- (1974). Class, Codes and Control. Vol. 1. Theoretical studies towards a sociology of language. London: R.K.P.

- (1981). "Codes, Modalities and the process of cultural reproduction: A model" en Anglo American Studies, Vol. 1.

DAVIES, B. (1976). Social Control and Education London: Methuen.

BERNBAUM, B. (1977). Knowledge md Ideology in Education. London: MacMillan. 